\title{
Capim-braquiária sob lotação contínua e com altura única ou variável durante as estações do ano: dinâmica do perfilhamento ${ }^{1}$
}

\author{
Manoel Eduardo Rozalino Santos ${ }^{2}$, Dilermando Miranda da Fonseca ${ }^{3}$, Virgílio Mesquita Gomes ${ }^{4}$, \\ Domicio do Nascimento Júnior ${ }^{3}$, Carlos Augusto de Miranda Gomide ${ }^{5}$, André Fischer Sbrissia ${ }^{6}$
}

\author{
1 Pesquisa financiada pelo CNPq. \\ 2 Pós-doutorando do Departamento de Zootecnia - Universidade Federal de Viçosa. Bolsista do CNPq. \\ ${ }^{3}$ Departamento de Zootecnia - Universidade Federal de Viçosa. \\ ${ }^{4}$ Doutorando do Departamento de Zootecnia - Universidade Federal de Viçosa. Bolsista da FAPEMIG. \\ 5 Embrapa Gado de Leite. \\ ${ }^{6}$ Universidade do Estado de Santa Catarina.
}

RESUMO - Objetivou-se estabelecer estratégias de manejo do pastejo, sob lotação contínua, que otimizem o padrão natural de perfilhamento da Brachiaria decumbens cv. Basilisk. Duas estratégias de manejo do pastejo foram estudadas: em uma, o pasto foi mantido com $25 \mathrm{~cm}$ de altura média durante todo o período experimental; e na outra foi mantido em $15 \mathrm{~cm}$ de altura média durante o inverno, com aumento para $25 \mathrm{~cm}$ a partir do início da primavera. Adotou-se o esquema de parcelas subdivididas em delineamento em blocos casualizados com quatro repetições. Consideraram-se como fator primário as estratégias de manejo do pastejo, caracterizadas pelas alturas médias em que os pastos foram mantidos durante as estações do ano (inverno, primavera e verão) e, como fator secundário, as medidas ao longo do período experimental. A taxa de aparecimento de perfilho (4,7\%), a taxa de mortalidade $(4,7 \%)$ e o índice de estabilidade $(0,998)$ foram menores no inverno. Nesta estação, contudo, a taxa de sobrevivência de perfilho foi maior (95,3\%). Em comparação aos pastos mantidos com 25 cm, aqueles manejados com 15 cm de altura média no inverno apresentaram maiores taxas de aparecimento de perfilho $(34,2 \%)$ e índice de estabilidade $(1,065)$. O florescimento do capim-braquiária ocorreu apenas no verão e com pouca intensidade (0,5\%). A otimização da renovação de perfilhos no pasto de $B$. decumbens cv. Basilisk sob lotação contínua ocorre com seu rebaixamento para $15 \mathrm{~cm}$ no início do inverno e seu posterior aumento para $25 \mathrm{~cm}$ no início da primavera.

Palavras-chave: altura do pasto, aparecimento de perfilho, Brachiaria decumbens, manejo do pastejo, mortalidade de perfilho

\section{Signalgrass under continuous stocking with fixed or variable height during the seasons: tillering dynamics}

\begin{abstract}
The experiment was conducted to establish management strategies of grazing under continuous stocking that optimize the natural pattern of tillering of Brachiaria decumbens cv. Basilisk. Two strategies of grazing management were studied: in one, the grass was maintained with $25-\mathrm{cm}$ mean height throughout the experimental period, and in the other, $15-\mathrm{cm}$ mean height during the winter, rising to $25 \mathrm{~cm}$ from beginning of spring. The split-plot in randomized block design with four replications was adopted. The strategies of grazing management corresponded to primary factor, characterized by average heights of pastures during the seasons of the year (winter, spring and summer). The seasons corresponded to secondary factor and consisted of measures over experimental period. The rates of tillers appearance (4.7\%), death (4.7\%) and stability index (0.998) were lower in winter. During this season, however, the tiller survival rate was higher (95.3\%). Compared with pastures maintained at $25 \mathrm{~cm}$, those managed with $15 \mathrm{~cm}$ in winter had higher tiller appearance rate (34.2\%) and stability index (1.065). The signalgrass flowering occurred only in the summer and with low intensity (0.5\%). Optimization for renewal of tillers in B. decumbens cv. Basilisk pasture under continuous stocking occurs with its decrease to $15 \mathrm{~cm}$ at the beginning of winter and subsequent increase to $25 \mathrm{~cm}$ in early spring.
\end{abstract}

Key Words: Brachiaria decumbens, grazing management, sward height, tiller appearance, tiller mortality

\section{Introdução}

Quando bem manejado, o pasto é perene, mas seus perfilhos possuem ciclo de vida limitado, desse modo, a persistência do pasto depende de sua capacidade de emitir novos perfilhos para substituir aqueles que morrem (Colvill \& Marshall, 1984). Realmente, o número de perfilhos no pasto depende do equilíbrio entre as taxas 
de aparecimento e de mortalidade de perfilhos (Lemaire \& Chapman, 1996).

O número de folha formada determina a taxa potencial de aparecimento de perfilho, porque o desenvolvimento do perfilho ocorre a partir do desenvolvimento da gema axilar de cada fitômero (Nelson, 2000). Porém, o potencial de perfilhamento só pode ser atingido quando o índice de área foliar do pasto é baixo, pois a ativação das gemas para formação de novos perfilhos depende da quantidade e da qualidade de luz (Deregibus et al., 1983).

A taxa de aparecimento, juntamente com a taxa de sobrevivência de perfilhos, determina a densidade populacional de perfilhos no pasto e influencia a participação de perfilhos com diferentes faixas etárias no pasto, caracterizando a intensidade com que a renovação de plantas ocorre sob condições específicas de manejo. Por outro lado, a taxa de florescimento determina o percentual de perfilhos em estádio reprodutivo no pasto.

A taxa de aparecimento de perfilho constitui característica central na dinâmica de perfilhamento, uma vez que é determinante do número de perfilhos vegetativos, reprodutivos e mortos no pasto, indicando a importância de se assegurar o perfilhamento contínuo do pasto independentemente dos métodos de pastejo e das estratégias de manejo utilizados.

O somatório dos perfilhos vegetativos, reprodutivos e mortos no pasto determina sua estrutura, que pode ser modificada e controlada pelo manejo do pastejo. Nesse sentido, variações nas características estruturais resultam em alterações no microclima do pasto, o que desencadeiam novas respostas na dinâmica do perfilhamento.

Desse modo, a intensidade com que os processos de aparecimento, sobrevivência e florescimento de perfilhos ocorrem no pasto determina o tamanho e o perfil da população de perfilhos (faixa etária e, ou, estádio de desenvolvimento), o que interfere no valor nutritivo da forragem, no potencial produtivo e na competitividade do pasto.
Assim, este trabalho foi desenvolvido com o objetivo de identificar estratégias de manejo do pastejo, sob lotação contínua, que assegurem o padrão natural de dinâmica de perfilhamento do pasto de Brachiaria decumbens cv. Basilisk sob lotação contínua e, com efeito, garantam sua persistência e evitem a degradação do pasto pelo pastejo inadequado.

\section{Material e Métodos}

O experimento foi realizado de junho de 2008 a março de 2009 no Setor de Forragicultura do Departamento de Zootecnia, na Universidade Federal de Viçosa (UFV), localizada em Viçosa, Minas Gerais. As coordenadas geográficas aproximadas do local do experimento são $20^{\circ} 45^{\prime}$ de latitude Sul e $42^{\circ} 51^{\prime}$ de longitude Oeste e a altitude é de $651 \mathrm{~m}$.

Foi utilizada uma pastagem de Brachiaria decumbens cv. Basilisk (capim-braquiária), estabelecida em Latossolo Vermelho-Amarelo de textura argilosa e relevo medianamente ondulado (Embrapa, 1999). O capimbraquiária restabeleceu naturalmente nessa área em 1997, após o plantio e avaliação do capim-elefante (Pennisetum purpureum cv. Mott). Desde 1997, essa pastagem vem sendo utilizada para desenvolvimento de projetos de pesquisa e, antes da implementação desse experimento, a pastagem já se encontrava dividida em oito piquetes, de 0,25 a 0,40 ha, além de uma área de reserva, totalizando aproximadamente 3,0 ha.

O clima da região de Viçosa é do tipo Cwa (Köppen, 1948), com precipitação anual em torno de 1.340 mm e umidade relativa do ar média de $80 \%$. As temperaturas médias máxima e mínima são de 22,1 e $15{ }^{\circ} \mathrm{C}$. Os dados climáticos registrados durante o período experimental foram obtidos na estação meteorológica do Departamento de Engenharia Agrícola da UFV, situada a cerca de $500 \mathrm{~m}$ da área experimental (Tabela 1).

Tabela 1 - Médias mensais da temperatura média diária, insolação, precipitação pluvial total mensal e evaporação total mensal durante junho de 2008 a março de 2009

\begin{tabular}{lcccc}
\hline Mês & Temperatura média do ar $\left({ }^{\circ} \mathrm{C}\right)$ & Insolação (hora/dia) & Precipitação pluvial (mm) & Evaporação $(\mathrm{mm})$ \\
\hline Junho/2008 & 16,7 & 6,2 & 12,7 & 10,2 \\
Julho/2008 & 15,4 & 8,2 & 15,4 & 73,9 \\
Agosto/2008 & 16,7 & 7,3 & 150,0 & 87,1 \\
Setembro/2008 & 18,7 & 4,4 & 41,4 & 101,5 \\
Outubro/2008 & 21,6 & 5,6 & 223,8 & 89,0 \\
Novembro/2008 & 21,0 & 3,7 & 626,0 & 65,8 \\
Dezembro/2008 & 21,3 & 11,1 & 250,7 & 270,8 \\
Janeiro/2009 & 22,5 & 13,2 & 22,5 & 63,3 \\
Fevereiro/2009 & 23,0 & 6,6 & 231,9 & 60,1 \\
Março/2009 & 22,8 & 5,8 & & \\
\hline
\end{tabular}


Foram avaliadas duas estratégias de manejo do pastejo. Em uma, o pasto foi mantido com $25 \mathrm{~cm}$ de altura média durante todo o período experimental. A outra correspondeu à manutenção do pasto em $15 \mathrm{~cm}$ de altura média durante $\mathrm{o}$ inverno, com aumento para $25 \mathrm{~cm}$ a partir do início da primavera. Adotou-se o esquema de parcelas subdivididas e o delineamento em blocos casualizados com quatro repetições. As estratégias de manejo do pastejo corresponderam ao fator primário (parcela), caracterizadas pelas alturas médias em que os pastos foram mantidos sob lotação contínua durante as estações do ano: inverno, primavera e verão. Estas corresponderam ao fator secundário (subparcela) e consistiram de medidas ao longo do período experimental. O critério utilizado para definição dos blocos foi a variação de relevo existente na área experimental.

Desde junho de 2007, os oito piquetes da área experimental vinham sendo manejados sob lotação contínua com taxa de lotação variável para manter a altura média do pasto em $25 \mathrm{~cm}$. Dessa forma, para a implementação dos tratamentos, em meados de junho de 2008 , os quatro piquetes descritos anteriormente tiveram a altura média do pasto rebaixada para $15 \mathrm{~cm}$. Para isso, aumentou-se a taxa de lotação nos mesmos, utilizando-se bovinos em recria com peso médio de aproximadamente $200 \mathrm{~kg}$. Assim, conseguiu-se que, em um período de cerca de 15 dias, as metas de alturas almejadas $(15 \mathrm{~cm})$ fossem alcançadas. Por outro lado, os outros quatros piquetes permaneceram com o pasto em cerca de $25 \mathrm{~cm}$ de altura média, com ausência de animais desde maio de 2008. Somente a partir do início de outubro de 2008, todos os piquetes voltaram a ser utilizados, concomitantemente, com animais, e os pastos foram manejados sob lotação contínua e taxa de lotação variável para manter sua altura média em aproximadamente $25 \mathrm{~cm}$.

O monitoramento das alturas dos pastos foi realizado por meio de medidas em 50 pontos de cada piquete, utilizando-se instrumento construído com dois tubos de PVC, um no interior do outro. O tubo interno possui escala com divisões de $1 \mathrm{~cm}$ e uma haste fixa e metálica (prego) que desliza ao longo de uma fenda no tubo externo. O critério para a mensuração da altura do pasto correspondeu à distância desde a superfície do solo até as folhas localizadas na parte superior do dossel. Durante a primavera e o verão, as medidas das alturas dos pastos ocorreram duas vezes por semana, enquanto que no inverno a frequência dessas medições foi reduzida para uma vez por semana. Para o controle da altura do pasto, bovinos com cerca de $200 \mathrm{~kg}$ de peso corporal foram retirados ou colocados nos piquetes quando as alturas dos pastos estavam abaixo ou acima, respectivamente, do valor almejado.
O manejo da adubação foi feito de acordo com recomendações de Cantarutti et al. (1999) e com base na análise química do solo realizada em outubro de 2008, que apresentou os seguintes resultados: $\mathrm{pH}$ em $\mathrm{H}_{2} \mathrm{O}$ : 4,79; $\mathrm{P}: 1,5$ (Mehlich-1) e K: $86 \mathrm{mg} / \mathrm{dm}^{3} ; \mathrm{Ca}^{2+}: 1,46 ; \mathrm{Mg}^{2+}: 0,32 \mathrm{e} \mathrm{Al}^{3+}$ : $0,19 \mathrm{cmol}_{\mathrm{c}} / \mathrm{dm}^{3}(\mathrm{KCl} 1 \mathrm{~mol} / \mathrm{L})$. Foi realizada adubação em toda área experimental com a aplicação de $100 \mathrm{~kg} / \mathrm{ha}$ de $\mathrm{Ne}$ $\mathrm{K}_{2} \mathrm{O}$, bem como $25 \mathrm{~kg} /$ ha de $\mathrm{P}_{2} \mathrm{O}_{5}$, usando o formulado 20-05-20. Essas doses foram divididas em duas aplicações iguais, que ocorreram nos dias 11/11/2008 e 15/12/2008.

Todas as avaliações ocorreram a partir de julho de 2008 até março de 2009 e foram realizadas em intervalos de 28 dias. O número de perfilhos foi determinado pela colheita de três amostras por piquete em locais do pasto que representavam sua condição média. Foram colhidos, ao nível do solo, todos os perfilhos contidos no interior de um quadrado de 0,25 m de lado. Esses perfilhos foram acondicionados em sacos plásticos e, em seguida, levados ao laboratório, onde foram classificados e quantificados. Os perfilhos vivos com inflorescência foram classificados como reprodutivos; os vivos que não tinham inflorescência foram denominados de vegetativos; e aqueles cujo colmo estava totalmente necrosado foram classificados como mortos.

Para avaliação da dinâmica do perfilhamento, em cada unidade experimental (piquete), foram delimitados três locais, com área de $0,0625 \mathrm{~m}^{2}$, representativos da condição média inicial do pasto. Esses locais foram demarcados utilizando-se moldura metálica pintada na cor branca e com formato de um quadrado de $25 \mathrm{~cm}$ de lado. Esta moldura foi fixada ao solo por meio de dois grampos metálicos e não foi removida até o término do experimento. No início da avaliação, todos os perfilhos dentro das molduras, foram contados e marcados com arame liso revestido de plástico colorido. A partir daí, a cada 30 dias, todos perfilhos foram novamente contados e os perfilhos novos foram marcados com arame de cor diferente para identificar as novas gerações. Os perfilhos mortos tiveram seus arames de identificação retirados. Considerou-se perfilho morto aquele desaparecido, seco ou em estádio avançado de senescência.

Com esses dados, calcularam-se as taxas de aparecimento de perfilho (TApP), de mortalidade de perfilho (TMoP), de sobrevivência de perfilho (TSoP) e de florescimento de perfilho (TFloP), de acordo com metodologia proposta por Carvalho et al. (2000). Adicionalmente, a partir dos dados originais de contagem de perfilhos foram geradas, mensalmente, curvas de variação mensal no número das gerações de perfilhos nos pastos.

O cálculo do índice de estabilidade da população de perfilhos foi feito pela equação $\mathrm{P}_{\mathrm{f}} / \mathrm{P}_{\mathrm{i}}=\mathrm{TSoP}(1+\mathrm{TApP})$, 
sendo que $\mathrm{P}_{\mathrm{f}} / \mathrm{P}_{\mathrm{i}}$ corresponde à população atual ou final de perfilhos $\left(\mathrm{P}_{\mathrm{f}}\right)$ expressa como percentual da população original ou inicial de perfilhos $\left(\mathrm{P}_{\mathrm{i}}\right)$ em determinado período de avaliação qualquer (Sbrissia, 2004). Para o cálculo do índice de estabilidade, utilizaram-se valores decimais de TSoP e TApP.

Para análise dos dados, primeiramente, foi realizada uma comparação descritiva das médias das variáveis respostas, por meio de gráficos, para identificar os meses onde seus padrões de variações foram similares. Com base nisso, os resultados foram agrupados em função das estações do ano, ou seja, para cada variável resposta, os dados mensurados em três meses foram usados para fazer uma média e gerar um valor apenas para a estação do ano correspondente, de modo que esse agrupamento foi realizado da seguinte maneira:

Inverno: julho, agosto e setembro de 2008;

Primavera: outubro, novembro e dezembro de 2008;

Verão: janeiro, fevereiro e março de 2009.

Apenas para a variável taxa de florescimento de perfilho não foi efetuada análise estatística, uma vez que um número muito grande de valores iguais a zero foi registrado neste tipo de avaliação.

As demais análises dos dados experimentais foram feitas usando o Sistema para Análises Estatísticas - SAEG, versão 8.1 (Universidade Federal de Viçosa, 2003). Para cada característica, procedeu-se à análise de variância em delineamento de blocos casualizados, em esquema de parcelas subdivididas, com o objetivo de desdobrar a soma de quadrados de tratamentos nas partes devido a cada fator e na parte devido à interação entre os fatores. Quando a interação entre os fatores não foi significativa, realizou-se a comparação entre as médias marginais dos níveis do fator primário (estratégia de manejo do pastejo) ou secundário (estação do ano), de acordo com a significância dos mesmos. Quando a interação entre os fatores foi significativa, procedeu-se à comparação dos níveis de um fator em separado para cada nível do outro fator. As médias do fator primário foram comparadas pelo teste $\mathrm{F}$, enquanto que as do fator secundário, pelo teste de Tukey. Todas as análises estatísticas foram realizadas ao nível de significância de até $10 \%$ de probabilidade.

\section{Resultados e Discussão}

A taxa de aparecimento de perfilhos (TApP) foi menor $(\mathrm{P}<0,10)$ no inverno e manteve-se em patamares mais altos na primavera e no verão. A estratégia de manejo do pastejo também afetou a TApP, que incrementou com o rebaixamento do pasto para 15 cm no inverno em comparação à manutenção dos mesmos em $25 \mathrm{~cm}$ em todas as estações (Tabela 2).

A menor TApP no inverno foi devido às condições de clima desfavoráveis ao crescimento do pasto nessa estação, caracterizada por menores temperatura, precipitação e insolação diária (Tabela 1). Essas condições ambientais influenciam o desenvolvimento das gemas localizadas nas porções basais e, ou, laterais da planta (Pedreira et al., 2001). Por outro lado, na primavera e no verão, quando as condições de clima foram propícias ao desenvolvimento do pasto, a TApP foi superior.

Durante todo o período experimental, no pasto mantido com 15 cm no inverno, a TApP foi, em média, 35\% superior àquela observada no pasto mantido sempre a $25 \mathrm{~cm}$. Esse resultado indica que pasto mais baixo no inverno apresenta melhor condição de rebrotação nessa estação e nas estações subsequentes, sobretudo na primavera.

Em dosséis baixos, a maior incidência de luz na base das plantas estimula o perfilhamento (Carvalho et al., 2000; Sbrissia \& Da Silva, 2008), especialmente quando a condição ambiental volta a ser favorável ao desenvolvimento da planta, situação comum na primavera. Em adição, pasto com menor altura média no inverno possuiu menor taxa de senescência foliar (Santos, 2009), o que certamente reduziu a quantidade de tecidos mortos no estrato inferior do pasto, propiciando maior luminosidade sobre as gemas basais e, por conseguinte, estimulando o perfilhamento.

A taxa de mortalidade de perfilho (TMoP) também foi influenciada $(\mathrm{P}<0,10)$ pela estação do ano, pois foram observados valores decrescentes na primavera, no verão e no inverno, respectivamente. Entretanto, não houve efeito $(\mathrm{P}>0,10)$ das estratégias de manejo do pastejo sobre a TMoP (Tabela 3).

Durante o inverno, apesar da ausência de diferença estatística $(\mathrm{P}>0,10)$, a TMoP foi quase duas vezes maior no pasto rebaixado para $15 \mathrm{~cm}$ em relação ao pasto manejado com $25 \mathrm{~cm}$. Possivelmente, com o rebaixamento do pasto, houve maior eliminação do meristema apical dos perfilhos, o que pode determinar sua mortalidade (Gomide, 1994). Por

Tabela 2 - Taxa de aparecimento de perfilho basal (\%) em pastos de capim-braquiária manejados sob lotação contínua e com altura fixa ou variável durante as estações do ano

\begin{tabular}{ccccc}
\hline $\begin{array}{c}\text { Altura do } \\
\text { pasto }(\mathrm{cm})\end{array}$ & \multicolumn{3}{c}{ Estação do ano } & Média \\
\cline { 2 - 4 } & Inverno & Primavera & Verão & \\
\hline 25 & 3,0 & 35,9 & 37,3 & $25,4 \mathrm{~B}$ \\
$15-25$ & 6,5 & 51,0 & 45,3 & $34,2 \mathrm{~A}$ \\
Média & $4,7 \mathrm{~b}$ & $43,5 \mathrm{a}$ & $41,3 \mathrm{a}$ & \\
\hline
\end{tabular}

Médias seguidas de mesma letra minúscula na linha e maiúscula na coluna não diferem $(P>0,10)$ entre si. 
outro lado, nas demais estações, as diferenças de TMoP entre as estratégias de manejo foram de menor magnitude.

É importante salientar que, no inverno, as magnitudes dos valores de TMoP foram baixas (Tabela 3), o que não compromete a persistência dos pastos, mesmo naqueles rebaixados para $15 \mathrm{~cm}$. Realmente, nestes, a TMoP $(6,1 \%)$ foi inferior à $\mathrm{TApP}(6,5 \%)$, o garantiu um balanço positivo entre aparecimento e mortalidade de perfilhos (Tabelas 2 e 3 ).

A maior TMoP na primavera (Tabela 3) é coincidente com a maior TApP nessa mesma estação (Tabela 2), o que indica alta renovação de perfilhos no pasto de capimbraquiária. Na estação seguinte (verão), a TMoP reduziu, mas a TApP continuou alta, demonstrando que a renovação de perfilhos, iniciada na primavera, continuou no verão.

O padrão de resposta do capim-braquiária em relação à TApP e à TMoP caracteriza a estratégia dessa planta forrageira em manter e assegurar sua perenidade através da alta renovação de perfilhos na primavera e no verão. A partir do verão, quando as condições de meio começam progressivamente a desfavorecer o desenvolvimento do capim-braquiária, é possível que outras estratégias de perenização dessa espécie sejam desencadeadas, como a produção de sementes via florescimento dos perfilhos, que iniciou no final do verão.

A renovação de perfilhos ocorrida na primavera e no verão indica que a idade média da população de perfilhos no pasto foi reduzida, o que tem implicações agronômicas importantes. Realmente, as características morfogênicas são influenciadas pela idade do perfilho, de forma que perfilhos mais jovens possuem maiores taxas de aparecimento e alongamento de folhas (Barbosa, 2004, Paiva, 2009). Com isso, pode-se afirmar que o aumento da produção de forragem nos pastos de capim-braquiária no início da primavera (Fagundes et al., 2005; Moreira et al., 2009) ocorre devido, dentre outros fatores, à menor idade média dos perfilhos no pasto. Além disso, perfilhos mais jovens são de melhor composição morfológica e valor nutritivo (Santos et al., 2006) e mais responsivos à adubação nitrogenada, o que potencializa os benefícios de práticas agronômicas e de uso de insumos (Da Silva et al., 2008).

Tabela 3 - Taxa de mortalidade de perfilho basal (\%) em pastos de capim-braquiária manejado sob lotação contínua e com altura fixa ou variável durante as estações do ano

\begin{tabular}{ccccc}
\hline $\begin{array}{c}\text { Altura do } \\
\text { pasto }(\mathrm{cm})\end{array}$ & \multicolumn{3}{c}{ Estação do ano } & \multirow{2}{*}{ Média } \\
\cline { 2 - 4 } & Inverno & Primavera & Verão & \\
\hline 25 & 3,4 & 21,6 & 17,3 & $14,1 \mathrm{~A}$ \\
$15-25$ & 6,1 & 20,7 & 12,8 & $13,2 \mathrm{~A}$ \\
Média & $4,7 \mathrm{c}$ & $21,2 \mathrm{a}$ & $15,1 \mathrm{~b}$ & \\
\hline
\end{tabular}

Médias seguidas de mesma letra minúscula na linha e maiúscula na coluna não diferem $(P>0,10)$ entre si.
A taxa de sobrevivência de perfilho (TSoP) não foi modificada pelas estratégias de manejo do pastejo, porém foi influenciada pela estação do ano (Tabela 4). Os maiores valores de TSoP, em ordem decrescente, ocorreram no inverno, no verão e na primavera. A maior sobrevivência dos perfilhos no inverno é reflexo da menor taxa de mortalidade nesse período (Tabela 3 ) e pode ser estratégia ecológica do capim-braquiária de conservação de nutrientes. Essa estratégia é interessante, pois a absorção dos nutrientes pela planta, via fluxo de massa e, ou, difusão, é dificultada no inverno em razão do déficit hídrico no solo (Novaes \& Smyth, 1999).

De outra forma, a menor sobrevivência de perfilhos na primavera indica mudança de estratégia ecológica do capimbraquiária, pois a planta forrageira, provavelmente, passou a priorizar a translocação dos nutrientes dos tecidos em senescência para os tecidos em crescimento (Taiz \& Zeiger, 2006). Em adição, o decréscimo da sobrevivência de perfilho na primavera comprova que a idade média da população de perfilhos no pasto foi menor nessa estação.

Outro aspecto importante e interferente na TSoP diz respeito à ausência de pastejo apenas durante os meses de inverno, o que também pode ter contribuído para a superior sobrevivência dos perfilhos de capim-braquiária nessa estação.

A análise dos dados das taxas de aparecimento e de sobrevivência de perfilho evidencia a existência de um mecanismo compensatório entre essas características nos pastos de capim-braquiária, que tende a estabilizar a população de perfilhos e, assim, garantir sua persistência na área sob condições ambientais distintas. Com efeito, no inverno, a fim de compensar a redução na taxa de aparecimento (Tabela 2), os perfilhos sobreviveram por mais tempo (Tabela 4). Já na primavera e verão, períodos em que a taxa de aparecimento foi maior (Tabela 2), os perfilhos tiveram menor longevidade (Tabela 4). Essa compensação é, portanto, determinante da magnitude da população de perfilho no pasto sob condições ambientais específicas.

Outra forma de analisar, concomitantemente, o aparecimento e a sobrevivência de perfilhos no pasto pode

Tabela 4 - Taxa de sobrevivência de perfilho basal (\%) em pastos de capim-braquiária manejado sob lotação contínua e com altura fixa ou variável durante as estações do ano

\begin{tabular}{ccccc}
\hline $\begin{array}{c}\text { Altura do } \\
\text { pasto }(\mathrm{cm})\end{array}$ & \multicolumn{3}{c}{ Estação do ano } & Média \\
\cline { 2 - 4 } & Inverno & Primavera & Verão & \\
\hline 25 & 96,6 & 78,4 & 82,7 & $85,9 \mathrm{~A}$ \\
$15-25$ & 93,9 & 79,3 & 87,2 & $86,8 \mathrm{~A}$ \\
Média & $95,3 \mathrm{a}$ & $78,8 \mathrm{c}$ & $84,9 \mathrm{~b}$ & \\
\hline
\end{tabular}

Médias seguidas de mesma letra minúscula na linha e maiúscula na coluna não diferem $(\mathrm{P}>0,10)$ entre si. 
ser conseguida pelo cálculo do índice de estabilidade (IE) (Tabela 5). De forma geral, IE menor que 1 indica que o pasto tem taxa de aparecimento relativa menor do que a taxa de sobrevivência para um mesmo período, indicando instabilidade da população de plantas no pasto (Sbrissia, 20004). Nesse sentido, constatou-se que o IE foi maior na primavera e no verão, quando cotejado ao inverno. Adicionalmente, a manutenção do pasto mais baixo durante o inverno resultou em maior IE em comparação aos pastos mantidos com maior altura média no inverno (Tabela 5).

Vale salientar que, mesmo no inverno, o IE do capimbraquiária foi praticamente igual a 1 , independentemente da estratégia de manejo do pastejo empregada. Dessa forma, deduz-se que os pastos de capim-braquiária mantiveram-se estáveis durante o inverno. Ademais, na primavera e no verão, a taxa de aparecimento de perfilho incrementou, em termos proporcionais, mais do que a diminuição ocorrida na taxa de sobrevivência dos perfilhos, o que resultou no acréscimo do IE dos pastos.

Com relação à estratégia de manejo do pastejo, a maior estabilidade da população de perfilhos nos pastos rebaixados para $15 \mathrm{~cm}$ no início do inverno, principalmente na primavera e no verão, se deve à otimização do balanço entre aparecimento e mortalidade de perfilhos nessa condição de manejo (Tabelas 2 e 3).

Nesse sentido, é possível afirmar que o pasto de capimbraquiária mantido com menor altura média no inverno torna-se mais estável, porque apresenta maior resistência e maior resiliência. Em verdade, o pasto de capim-braquiária mantido mais baixo no inverno é capaz de resistir melhor às condições climáticas desfavoráveis vigentes nessa estação (déficit hídrico e baixa temperatura) e nessa região (Zona da Mata de Minas Gerais). Ademais, o pasto de capim-braquiária manejado com menor altura no inverno também tem maior capacidade de retomar seu crescimento após o inverno (Tabela 2), o que demonstra sua maior resiliência.

A maior estabilidade em pastos baixos no inverno (15 cm) foi obtida em condições de clima desfavoráveis ao crescimento do pasto (Tabela 1) e características da Zona

Tabela 5 - Índice de estabilidade em pastos de capim-braquiária manejado sob lotação contínua e com altura fixa ou variável durante as estações do ano

\begin{tabular}{ccccc}
\hline $\begin{array}{c}\text { Altura do } \\
\text { pasto }(\mathrm{cm})\end{array}$ & \multicolumn{3}{c}{ Estação do ano } & Média \\
\cline { 2 - 4 } & Inverno & Primavera & Verão & \\
\hline 25 & 0,995 & 1,065 & 1,134 & $1,065 \mathrm{~B}$ \\
$15-25$ & 1,000 & 1,198 & 1,266 & $1,155 \mathrm{~A}$ \\
Média & $0,998 \mathrm{~b}$ & $1,131 \mathrm{a}$ & $1,200 \mathrm{a}$ & \\
\hline
\end{tabular}

Médias seguidas de mesma letra minúscula na linha e maiúscula na coluna não diferem $(\mathrm{P}>0,10)$ entre si. da Mata de Minas Gerais. Contudo, em regiões em que o clima é mais adverso ou bem mais restritivo à planta forrageira, tal como em localidades onde ocorrem geadas durante o inverno, é preciso realizar estudos específicos com o objetivo de verificar se o rebaixamento do pasto também é estratégia adequada de manejo do capim-braquiária.

Dentre as estações avaliadas, o florescimento do capim-braquiária ocorreu apenas no verão (Tabela 6) e, mesmo assim, com pouca intensidade. Resultado semelhante foi obtido por Moraes et al. (2006) em avaliação da $B$. decumbens cv. Basilisk sob lotação contínua e adubada com nitrogênio na mesma área experimental. Esses autores relataram que a maior emissão de perfilhos reprodutivos aconteceu nos meses de verão; e nos meses de inverno e primavera, o florescimento foi ínfimo. Da mesma forma e corroborando esses resultados, de acordo com revisão feita por Santos \& Bernardi (2005), a B. decumbens cv. Basilisk possui maior florescimento nos meses de janeiro e março (verão).

A partir dos dados originais de contagem de perfilhos, também foram gerados gráficos da dinâmica de perfilhamento do capim-braquiária, em que se pode observar o decréscimo mensal no número de perfilhos por geração e a oscilação mensal da população de perfilhos nos pastos (Figuras 1 e 2).

Em todas as estratégias de manejo do pastejo, houve menor densidade populacional de perfilho nos meses de inverno, porém o número de perfilho foi incrementado a partir de início de outubro (primavera). No início da primavera (outubro), houve aumento médio de $71 \%$ na população de perfilhos, independentemente da estratégia de manejo do pastejo avaliada, caracterizando intensa renovação de perfilho nessa estação. De acordo com Langer (1972), a produção de perfilhos é controlada pela disponibilidade de água, luz, temperatura enutrientes (principalmente nitrogênio) e, em menor escala, fósforo e potássio, além do estádio de desenvolvimento da planta. A ação de todos esses fatores, em conjunto e com magnitudes variáveis, determinara o aparecimento e a morte de perfilhos que aconteceram durante os meses do ano nos pastos de capim-braquiária.

Tabela 6 - Taxa de florescimento de perfilho basal (\%) em pastos de capim-braquiária manejado sob lotação contínua e com altura fixa ou variável durante as estações do ano

\begin{tabular}{ccccc}
\hline $\begin{array}{c}\text { Altura do } \\
\text { pasto }(\mathrm{cm})\end{array}$ & \multicolumn{3}{c}{ Estação do ano } & Média \\
\cline { 2 - 3 } & Inverno & Primavera & Verão & \\
\hline 25 & 0,0 & 0,0 & 0,2 & 0,1 \\
$15-25$ & 0,0 & 0,0 & 0,9 & 0,3 \\
Média & 0,0 & 0,0 & 0,5 & \\
\hline
\end{tabular}


De forma geral, os perfilhos marcados no início de julho mantiveram significativa contribuição durante o inverno e reduziu mais intensamente a partir da primavera (Figuras 1 e 2). Na primavera e no verão, as novas gerações de perfilhos foram as que mais contribuíram para a densidade populacional total de perfilhos. Esse padrão de resposta demonstra que, de meados da primavera em diante, pastos de capim-braquiária possuem pouca participação relativa de perfilhos mais velhos, oriundos de estações anteriores, o que confirma sua alta taxa de renovação de perfilhos.

Para a estratégia de manejo do pastejo caracterizada pela redução da altura média do pasto para $15 \mathrm{~cm}$ no inverno, observou-se que as participações relativas de perfilhos marcadas durante o inverno, primavera e verão corresponderam a 1,3\%; 18,5; e 80,2\%, respectivamente, de todos os perfilhos existentes no término do período experimental (março de 2009). Resultados semelhantes foram verificados com a estratégia de manejo em que os pastos foram mantidos com $25 \mathrm{~cm}$ de altura média durante todas as estações, onde os percentuais de perfilhos marcados no inverno, primavera e verão foram de 4,4\%; 14,4 ; e $81,2 \%$, respectivamente, em relação à população final de perfilhos

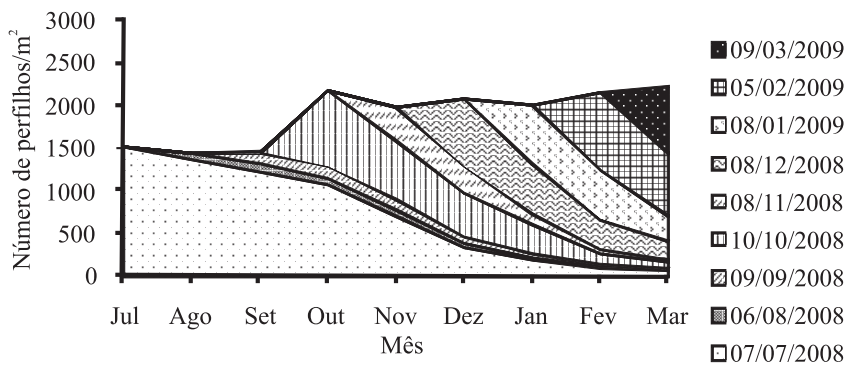

Figura 1 - Padrão demográfico do perfilhamento em pasto de capim-braquiária mantido em $25 \mathrm{~cm}$ de altura média sob lotação contínua com bovinos.

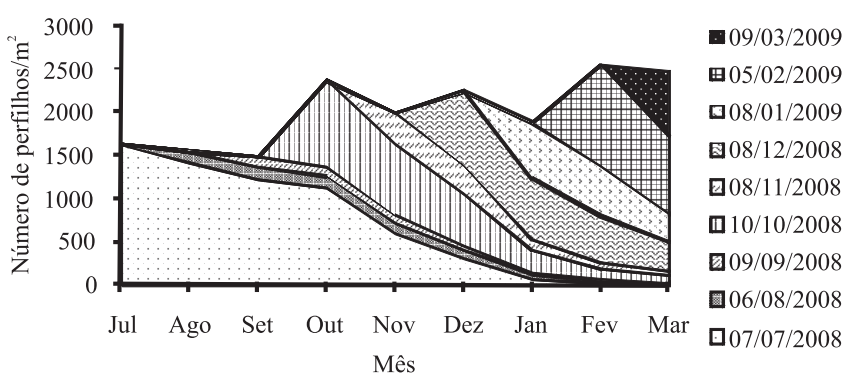

Figura 2 - Padrão demográfico do perfilhamento em pasto de capim-braquiária mantido em $15 \mathrm{~cm}$ de altura no inverno e $25 \mathrm{~cm}$ de altura na primavera e verão sob lotação contínua com bovinos. (março de 2009). Esses dados revelam alta renovação de perfilhos no verão em pastos de capim-braquiária. Assim, práticas de manejo devem ser idealizadas com o objetivo de permitir a expressão desse padrão de reposta, tais como a realização de adubações no verão, especialmente a nitrogenada (Moreira et al., 2009), e a inocorrência de subpastejo durante o verão.

É relevante sublinhar que a variação na estrutura do pasto durante o período experimental não foi completamente controlada nos locais de avaliação da dinâmica da população de perfilhos. No início do período experimental foram escolhidos locais que representavam as condições médias dos pastos, porém ocorreram mudanças na altura das plantas nesses locais no decorrer do período experimental, em virtude da variabilidade temporal na estrutura horizontal do pasto, inerente ao ecossistema pastagem (Santos, 2009). Como os locais de avaliação foram fixos nos pastos, as alterações nas taxas de aparecimento e mortalidade de perfilhos devem ser atribuídas não apenas aos efeitos de tratamentos, mas também às variações nas estruturas do pasto, que alteraram o microclima em que a dinâmica do perfilhamento foi avaliada. Nesse contexto, ao término do período experimental, ocorreram variações nas alturas dos pastos nos locais de avaliação da dinâmica de perfilhos em relação à altura média do pasto. De fato, nos locais de avaliação da dinâmica de perfilhamento, o capim-braquiária deveria estar com altura média de $25 \mathrm{~cm}$ ao término do experimento, o que não ocorreu (Figura 3).

A metodologia de avaliação da dinâmica da população de perfilhos utilizada nesse trabalho também pode ter superestimado os valores de taxa de aparecimento e de mortalidade de perfilhos e, com efeito, influenciado os valores de densidade populacional de perfilhos visualizados

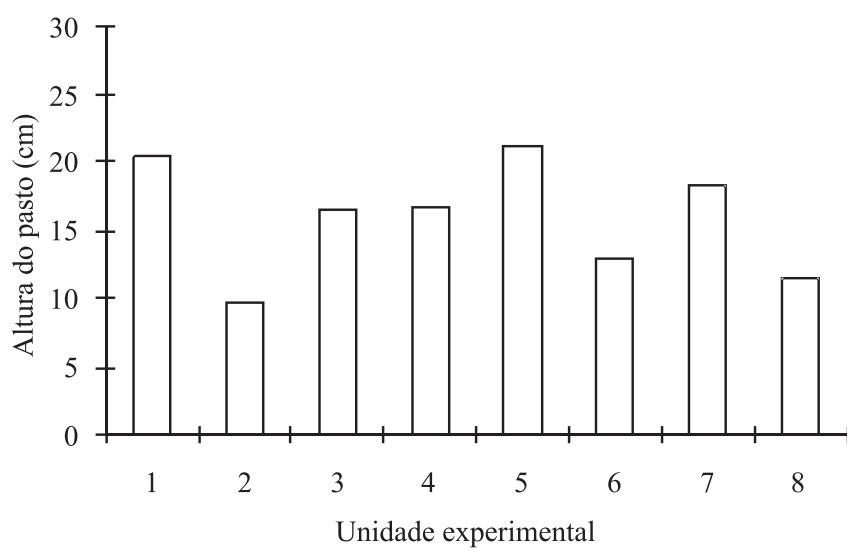

Figura 3 - Altura dos pastos nos locais das avaliações de dinâmica de perfilhamento do capim-braquiária manejado sob lotação contínua e com $25 \mathrm{~cm}$ de altura média no término do período experimental (março de 2009). 
nas figuras 1 e 2 . A manipulação mensal dos perfilhos pode ter permitido maior incidência de luz no dossel, o que provavelmente estimulou o perfilhamento. Além disso, a marcação mensal dos perfilhos, por mais cuidadosa que seja, também pode ter causado distúrbio nas plantas, principalmente nos perfilhos recém surgidos e de pequeno tamanho, o que também contribuiu para a sua mortalidade.

\section{Conclusões}

Para otimizar o padrão natural de renovação de perfilhos, é vantajoso manejar o pasto de Brachiaria decumbens cv. Basilisk sob lotação contínua por meio do seu rebaixamento para $15 \mathrm{~cm}$ no início do inverno e seu posterior aumento para $25 \mathrm{~cm}$ no início da primavera, quando comparado à manutenção do pasto em altura fixa (25 cm, em média) durante as estações do ano.

\section{Referências}

BARBOSA, R.A. Características morfofisiológicas e acúmulo de forragem em capim-Tanzânia (Panicum maximum Jacq. cv. Tanzânia) submetido a freqüências e intensidades de pastejo. 2004. 119f. Tese (Doutorado em Zootecnia) Universidade Federal de Viçosa, Viçosa, MG.

CANTARUTTI, R.B.; MARTINS, C.E.; CARVALHO, M.M. et al. Pastagens. In: RIBEIRO, A.C.; GUIMARÃES, P.T.G.; ALVAREZ V, V.H. (Eds.) Recomendações para uso de corretivos e fertilizantes em Minas Gerais - $5^{\text {a }}$ aproximação. Viçosa, MG: CFSEMG/UFV. 1999. p.332-341.

CARVALHO, C.A.B.; SILVA, S.C.; SBRISSIA, A.F. et al. Demografia do perfilhamento e taxas de acúmulo de matéria seca em capim tifton 85 sob pastejo. Scientia Agricola, v.57, n.4, p.591-600, 2000.

COLVILL, K.E.; MARSHALL, C. Tiller dynamics and assimilate partitioning in Lolium perenne with particular reference to flowering. Annals of Applied Biology, v.104, p.543-557, 1984.

DA SILVA, S.C.; NASCIMENTO JÚNIOR, D.; SBRISSIA, A.F. Dinâmica de população de plantas forrageiras em pastagens. In: SIMPÓSIO SOBRE MANEJO ESTRATÉGICO DA PASTAGEM, 4., 2008, Viçosa, MG. Anais... Viçosa, MG: UFV, 2008, p.75-100.

DEREGIBUS, V.A.; SANCHEZ, R.A.; CASAL, J.J. Effects of light quality on tiller production in Lolium spp. Plant Physiology, v.72, p.900-912, 1983.

EMBRAPA. Sistema brasileiro de classificação dos solos. Brasília: Embrapa-SPI; Rio de Janeiro: Embrapa-CNPS, 1999. 412p.

FAGUNDES, J.L.; FONSECA, D.M.; GOMIDE, J.A. et al. Acúmulo de forragem em pastos de Brachiaria decumbens adubados com nitrogênio. Pesquisa Agropecuária Brasileira, v.40, n.4, p.397-403, 2005.

GOMIDE, J.A. Fisiologia do crescimento livre de plantas forrageiras. In: PEIXOTO, A.M.; MOURA, J.C.; FARIA, V.P. (Eds).
Pastagem: fundamentos da exploração racional. Piracicaba, FEALQ-USP, 1994. p.1-14.

KÖPEN, W. Climatologia. Buenos Aires: Gráfica Panamericana, 1948. 478p.

LANGER, R.H.M. How grasses grow. 2.ed. London: Edward Arnold, 1972. 60p. (Studies in Biology, 34).

LEMAIRE, G.; CHAPMAN, D. Tissue flows in grazed plant communities. In: HODGSON, J.; ILliUS, A.W. (Eds.) The ecology and management of grazing systems. Wallingford: CAB International, 1996. p.3-36.

MORAIS, R.V.; FONSECA, D.M.; NASCIMENTO JUNIOR, D. et al. Demograf ia de perfilhos basilares em pastagem de Brachiaria decumbens adubada com nitrogênio. Revista Brasileira de Zootecnia, v.35, n.2, p.380-388, 2006.

MOREIRA, L.M.; MARTUSCELLO, J.A.; FONSECA, D.M. et al. Perfilhamento, acúmulo de forragem e composição bromatológica do capim-braquiária adubado com nitrogênio. Revista Brasileira de Zootecnia, v.38, n.9, p.1675-1684, 2009.

NELSON, C.J. Shoot morphological plasticity of grasses: leaf growth vs. tillering. In: LEMAIRE, G.; HODGSON, J.; MORAES, E. (Eds.) Grassland ecophysilogy and grazing ecology. Wallingford: CAB International, 2000. p.101-126.

NOVAES, R.F.; SMYTH, T.J. Fósforo em solo e em condições tropicais. Viçosa, MG: UFV, DPS, 1999. 399p.

PAIVA, A.J. Características morfogênicas e estruturais de faixas etárias de perfilhos em pastos de capim-marandu submetidos à lotação contínua e ritmos morfogênicos contrastantes. 2009. 104f. Dissertação (Mestrado em Ciência Animal e Pastagens) - Escola Superior de Agricultura "Luiz de Queiroz"/Universidade de São Paulo, Piracicaba.

PEDREIRA, C.G.S.; MELLO, A.C.L.; OTANI, L. O processo de produção de forragem em pastagens. In: REUNIÃO ANUAL DA SOCIEDADE BRASILEIRA DE ZOOTECNIA, 38., 2001, Piracicaba. Anais... Piracicaba: ESALQ, 2001. p.772-807.

SANTOS, M.E.R. Variabilidade espacial e dinâmica do acúmulo de forragem em pastos de capim-braquiária sob lotação contínua. 2009. 144f. Tese (Doutorado em Zootecnia) - Universidade Federal de Viçosa, Viçosa, MG.

SANTOS, P.M.; BERNARDI, A.C.C. Diferimento do uso de pastagens. In: SIMPÓSIO SOBRE MANEJO DA PASTAGEM, 22., 2005, Piracicaba. Anais... Piracicaba: FEALQ, 2005 p.95-118.

SANTOS, P.M.; CORSI, M.; PEDREIRA, C.G.S. Tiller cohort development and digestibilidade in Tanzania guinea grass (Panicum maximum cv. Tanzania) under three levels of grazing intensity. Tropical Grasslands, v.40, p.84-93, 2006.

SBRISSIA, A.F. Morfogênese, dinâmica do perfilhamento e do acúmulo de forragem em pastos de capim-Marandu sob lotação contínua. 2004. 171f. Tese (Doutorado em Agronomia) - Escola Superior de Agricultura "Luiz de Queiroz", Piracicaba.

SBRISSIA, A.F.; DA SILVA, S.C. Compensação tamanho/densidade populacional de perfilhos em pastos de capim-marandu. Revista Brasileira de Zootecnia, v.37, n.1, p.35-47, 2008.

TAIZ, L.; ZEIGER, E. Fisiologia vegetal. 3.ed. Porto Alegre: Artmed, 2006. 719p.

UNIVERSIDADE FEDERAL DE VIÇOSA - UFV. SAEG - Sistema de análises estatísticas e genéticas. Versão 8.1. Viçosa, MG: 2003. (Apostila). 